\title{
Nuevas imágenes, viejos racismos: la representación de los pueblos negros-afromexicanos en La negrada*
}

\section{New images, old racisms: The representation of black Afro-Mexican in La negrada}

\author{
ITZA AMANDA VARELA HUERTA**
}

\begin{abstract}
In this paper we review the forms in which black people have been represented in Mexican cinema and then analyze the film La negrada as a case study through a cultural studies' frame as a continuum in the ways in which the representation of black and Afromexican men and women happens from a racist perspective that accounts for the manner in which alter-phobic discourse in Mexico is normalized as part of everyday life, politics, academia and audiovisual-artistic production. With ethnographic and theoretical elements, the article concludes pointing which are the updates in racist and racialized discourses.
\end{abstract}

Key words: Ethnicity, afrodescendent, cinema, women

\begin{abstract}
Resumen
En este artículo se hace un recorrido por las formas de representación de "lo negro" en el cine mexicano, para después analizar desde los estudios culturales el caso de la película La negrada, como una continuidad en el modo en que las mujeres y los hombres negros afromexicanos siguen representados desde una óptica racista que da cuenta de cómo los discursos alterofóbicos en México son naturalizados en la vida cotidiana, la política, la academia y la producción audiovisual-artística. Con elementos etnográficos y teóricos, se concluye señalando cuáles son las actualizaciones de los discursos racistas y racializantes.
\end{abstract}

Palabras clave: etnicidad, afrodescendencia, cine, mujeres

\section{Introducción}

$\mathrm{E}$ l objetivo de este artículo es observar las continuidades y reescrituras -a veces presentadas como cambiosen la representación que se ha hecho de la población negra-afromexicana, sobre todo a la luz de la reciente película mexicana de ficción La negrada, de Jorge Pérez Solano (2018), y las discusiones que abrió este filme -el primero sobre personas negras-afromexicanas de la Costa Chica de Guerrero y Oaxaca-, que incluye además la participación de ciudadanos de la zona, que no son actores profesionales.

\footnotetext{
* Artículo recibido el 17/09/2019 y aceptado el 13/12/2019.

** Centro de Investigaciones y Estudios Superiores en Antropología Social-Pacífico Sur. Sierra Nevada 347, Loma Linda, 68024 Oaxaca de Juárez, Oax. <itza_amanda@yahoo.com.mx>. orcid: https: / / orcid.org/0000-0003-3160-7481.
} 
Me referiré en primer lugar y de manera sucinta a los estudios sobre la presencia de "lo negro"1 en el cine mexicano, para después discutir cuestiones relativas al abordaje teórico-metodológico de la representación en clave poscolonial y, al final, me centraré en un análisis de La negrada retomando los dos puntos anteriores con el objetivo de observar esta producción como parte de un régimen discursivo sobre alteridad y diferencia en el México del siglo xxi, así como su relación con el movimiento político por el reconocimiento de la población negra-afromexicana, en particular con la representación de las mujeres afro.

La metodología para analizar la película La negrada tiene un acercamiento analítico vinculado a las perspectivas éticas, políticas e históricas que subyacen al propio filme, por lo cual recuperaré algunos ejemplos de cómo se ha representado el sujeto histórico afrodescendiente en el cine mexicano.

Al principio me centraré en el problema de la representación de los pueblos negros-afromexicanos, en particular en el cine como medio de comunicación, con énfasis en las construcciones de significados en dicho soporte audiovisual. Por ello me parece fundamental diferenciar al sujeto político pueblo negro-afromexicano, movilizado desde hace unos 30 años para exigir espacios de representación política, histórica y legislativa, de la población de origen africano o afrodescendientes como sujeto de la investigación histórica o la política pública que funda la historia y la antropología mexicanas. Lo anterior para distinguir entre un sujeto político activo, con agencia y con potencialidad política en la vida actual de México, y para anotar cómo se construye históricamente el pasado de este sujeto desde la academia, la política pública y las narraciones de pasado, antes de las movilizaciones políticas por la construcción de una identidad étnica diferenciada. Esta diferenciación me parece útil para comprender cómo y desde cuáles espacios se nutren los discursos racialistas y racistas sobre la población afromexicana y sus diferentes demandas.

\section{Representaciones de "lo negro" en el cine mexicano del siglo $\mathrm{xx}$}

La creación y recreación sobre "lo negro" durante la época de oro del cine mexicano (1936-1951) es importante para este análisis dado que la industria cinematográfica nacional retomó una forma racista de representación de "lo negro", fincada en los estereotipos sobre los varones y las mujeres cubanas que ya participaban de la vida cultural y social en el país en la primera mitad del siglo xx. Gabriela Pulido Llano (2010) ha escrito ya sobre estos colectivos de migrantes cubanos entre 1920 y 1950: ha mostrado que su representación estuvo vinculada con las mujeres rumberas y los músicos que las acompañaban, y ha hecho hincapié en la generación de estereotipos que perviven y que construyeron, a partir del discurso audiovisual, la idea de las mujeres negras-afrodescendientes como cuerpos sexualmente disponibles, de una belleza exuberante, alegres y bailarinas; por otro lado, la idea del varón negro-afrodescendiente es la de un ser bohemio, ligado a la música, la sensualidad y la sexualidad.

El problema de esta representación de la alteridad negra-afrodescendiente en México también está asociado a cómo se construyó el tema del color y la racialización a mediados del siglo $\mathrm{xx}$, describiendo a la población jarocha de una forma despectiva, como ya señaló Pérez Montfort:

En el mundo cinematográfico la negritud ya pasaba como algo despectivo y poco recomendable en cualquier circunstancia comprometedora socialmente hablando. Tanto así que al describir una actitud "típica" de una chica urbana de mediados de los años cuarenta interpretada por Marga López en la película Mamá Inés (1945) de Fernando Soler, su novio la denuncia diciendo "andaba tan resbalosa que hasta hizo ruborizar al negro de la orquesta". Ser negro era pues sinónimo de extrema sensualidad, desparpajo, pero también de un ser relativamente reprobable.

Pero tal vez donde mejor pudo identificarse la continuidad de "lo negro" en la constitución del estereotipo jarocho fue en el ambiente musical y radiofónico de estos años. [...] Lo "rumbero y lo jarocho", al decir del compositor de moda, el supuestamente tlacotalpeño Agustín Lara, aunque no señala explícitamente su connotación negra, quedaría ligado a la enorme vertiente de música veracruzana que alimentó la educación sentimental popular a través de la radio [Pérez Montfort, 2007: 207-208].

Durante el siglo xx, la representación de "lo negro" en México tuvo como efecto una forma específica de racialización de esta población que, si bien estuvo fundada en los rasgos corporales visibles, también echó

1 En este artículo me refiero a "lo negro" como categoría racializante, es decir, vinculada al color y, por ende, a la idea biologicista de raza usada durante el siglo xx por diferentes instituciones sociales, culturales y de gobierno. Cuando escribo negro-afromexicano aludo a los sujetos sociales que se autoadscriben a la categoría política etnizada como negra, que buscan desvincularse de las categorías racistas. 
mano de la diferencia cultural a partir de la lógica de dividir a la población en tres razas diferentes (blanca, mestiza y negra) con cualidades y prácticas culturales diferenciadas. Estas divisiones están fundadas en las doctrinas sociales y científicas que durante esa época clasificaron y comprendieron la diferencia en el mundo; de esas clasificaciones, discursos y prácticas gubernamentales están construidas las alteridades mexicanas que se sostuvieron hasta el final de ese siglo y que el cine mexicano ayudó a configurar en el imaginario popular como una identidad mexicana:

¿Cuáles son esos imaginarios que se confunden en la pantalla y se cristalizan en nuestras mentes? Tanto en Enamorada como en Allá en el Rancho Grande se construye un imaginario basado en lo rural. Lo nacional y lo popular están fijados por un conjunto de signos que tienen su anclaje en una serie de campos simbólicos: el de los espacios sociales (la hacienda, la cantina, la aldea, la iglesia), el de las prácticas culturales (las carreras de caballos, las peleas de gallos, las serenatas, los matrimonios, etcétera), el de los sistemas simbólicos (el arte, la religión, la lengua) y el de los personajes (el caporal, el borracho, el hacendado, el charro, la dama de sociedad, el peón, las soldaderas, el revolucionario, el sacerdote, etcétera). Cada uno de estos campos viene a configurar una visión particular que necesariamente excluye otras prácticas culturales y otros espacios sociales [Silva Escobar, 2013: 24].

La única película en la cual participa población afromexicana es Fuego negro (1979), dirigida por Raúl Fernández Fernández y en la cual intervienen los actores Rolando Fernández, Yvonne de Carlo y Julio César Imbert. Este western sobre la esclavitud cuenta la historia de un hombre esclavizado que apoya la rebelión en contra de los amos blancos, pero al mismo tiempo está enamorado de la hija del hacendado que explota a las personas esclavizadas. Este filme, hablado en inglés y cuya locación es una hacienda, podría ser alguna historia de los procesos de esclavitud en Estados Unidos, sin embargo, hay diversos datos etnográficos que nos permiten pensar en la forma en que la población afromexicana fue invisibilizada.

La película fue filmada en Valerio Trujano, Cuicatlán, Oaxaca, una comunidad que este año inició un proceso de reflexión cultural sobre sus raíces negrasafrodescendientes. No es casual, por tanto, que Fernández eligiera este lugar de la región Cañada oaxaqueña para rodar su filme.

Durante el 19 y 20 de marzo de 2019 el profesorado y la población de Valerio Trujano llevaron a cabo la primera actividad vinculada con el proceso de iden- tificación afromexicano: se trató de una jornada de reconocimiento y memoria sobre su pasado afrodescendiente. En esa ocasión, las profesoras y pobladores invitaron a toda la población a llevar fotografías de sus familiares con biotipo afrodescendiente; también pidieron al profesor de historia de la telesecundaria que hiciera una ponencia sobre la historia del pueblo vinculada con la de la esclavización y, por último, llamaron a una proyección de la película Fuego negro para que las personas mayores del pueblo reconocieran a los familiares que participaron como actores "extras" para la película de una rebelión de personas esclavizadas durante el periodo colonial... pero que cuenta la historia de Estados Unidos en la locación de una hacienda donde efectivamente hubo esclavitud y donde apenas se construye la memoria de la misma.

Por otro lado, me parece importante nombrar una cinta que retrata a población "negra" o mulata, pero en la cual no interviene población afromexicana, sino actores con pintura oscura en la piel -estrategia conocida en inglés como blackface-; se trata de La negra Angustias (1949), filme de la época del cine de oro mexicano, dirigido por Matilde Landeta y que es la versión cinematográfica del libro del mismo título escrito por Francisco Rojas González. La historia se centra en la vida de Angustias, una aguerrida mujer tachada de marimacho por las mujeres de su pueblo, que se convertirá en comandante del movimiento zapatista de principios del siglo xx en el estado de Morelos.

Angustias se dedica a luchar por los más probes en el ejército zapatista y busca reivindicar a las mujeres que fueron vejadas por varones. Sin embargo, la historia retoma elementos sobre la raza cuando Angustias se enamora de un catrín que le enseña a leer, por quien dejará todas sus convicciones en nombre del amor romántico y de los estándares de belleza eurocéntricos, ya que en una de las escenas dice: "soy fea, refea. Soy negra por eso él no me quiere. Junto a él que es tan blanco como la leche, parezco yo un tizón. Si tan sólo fuera yo blanca como él".

\section{Antropología mexicana}

Incluso la antropología denominada no indigenista y antirracista de finales del siglo xx representa a la población de la Costa Chica reelaborando la idea de que la corporalidad y musicalidad de esta población es más festiva que la de los indígenas, mestizos mexicanos:

Tanto en Guerrero y Oaxaca como en Veracruz, la africanía se encuentra en la actitud vital de los afromestizos, en su concepción del mundo, en la mentalidad contrastante 
con la del indio; el afromestizo manifiesta en sus relaciones sociales una carga erótica que no presenta el indio; en los modos de vida y la gastronomía, en las formas de asumir la muerte y el nacimiento, el valor que tiene, como en África, la palabra; en su pasión por el ritmo y su extroversión. La idiosincrasia de los pueblos de la costa es, en definitiva, muy distante al resto de las regiones de México [Martínez Montiel, 2008: 309].

Aunque anteriormente la antropología consideraba a la población negra-afromexicana de la costa como "sensual" y a los indígenas resignados, como señala Veronique Flanet en su etnografía sobre la Costa, Viviré si Dios quiere: "Es en ese crisol donde viven juntos desde hace más de cuatro siglos la impulsividad y la sensualidad del negro, la superioridad del mestizo y la resignación del mixteco" (Flanet, 1977: 36).

En este punto, una pregunta pertinente es ¿cómo se representa a los pueblos negros-afromexicanos en el marco de su propia movilización? Y también si es posible observar cómo en las propuestas discursivas para hacerlos presentes en las políticas públicas y el imaginario nacional hay una narrativa diferente de las políticas de representación que Hall asienta:

El discurso racializado está estructurado por medio de un conjunto de oposiciones binarias. Existe la poderosa oposición entre "civilización" (blanca) y "salvajismo" (negro). Existe la oposición entre las características biológicas u orgánicas de las razas "blanca" y "negra", polarizada hacia sus extremos opuestos: cada una significadora de una diferencia absoluta entre "tipos" o especies humanas. Existen las ricas distinciones que se aglomeran alrededor del enlace supuesto, por un lado, entre las "razas" blancas y el desarrollo intelectual -refinamiento, aprendizaje y conocimiento, la creencia en la razón, la presencia de instituciones desarrolladas, el gobierno y la ley formal, y una "restricción civilizada" en su vida cívica, emocional y sexual, todo lo cual está asociado con "Cultura"y, por otro lado, la conexión entre las "razas" negras y cualquier cosa que sea instinto -la expresión abierta de la emoción y los sentimientos en lugar del intelecto, una ausencia de "refinamiento civilizado" en la vida sexual y social, una dependencia del rito y la costumbre, y la ausencia de instituciones cívicas desarrolladas, todo lo cual está ligado a la "Naturaleza"-. Finalmente, existe la polarización de la oposición entre la "pureza" racial por un lado y la "contaminación" que surge del intermatrimonio, la hibridez racial y la mezcla de razas [Hall, 2010: 426].
Otro referente importante para comprender la representación de "lo negro" en el siglo xx es el cine indigenista de principios de ese periodo, ya que éste creó una imagen de la población indígena mexicana que fue funcional a la concreción de un Estado proteccionista, con necesidades particulares de construcción de la identidad mestiza e indígena:

El indio se imaginó, convirtiéndose en una institución de lo que debían ser los indios reales: piedras, paisajes, magueyes o víctimas. En el cine mexicano las imágenes de los indígenas no tuvieron densidad histórica hasta muy entrado el siglo $\mathrm{xx}$, fueron despojados de sus características étnicas, modificados para ser comprendidos, se les representó para que los co-nacionales los asumieran y para que el extranjero los aplaudiera en sus deseos folcloristas de conocer "lo mexicano" [Nahmad Rodríguez, 2007: 113].

En este momento, así como se instituye desde el poder estatal la imagen del indio rural, pobre, estéticamente diferenciado, se genera el silenciamiento de la representación negra-afromexicana en dos temporalidades específicas: en la construcción del pasado histórico y en la vida cotidiana de los años veinte y treinta del siglo $\mathrm{xx}$, es decir, la presencia negra-afrodescendiente en México no es narrada ni como elemento fundamental de las narraciones del pasado ni tampoco como parte de la actualidad.

Si bien argumento más adelante que el sujeto político negro-afromexicano se constituye a finales de los años noventa, la población etnicizada como negra por Aguirre Beltrán en el periodo posrevolucionario ya era parte de los planes y programas gubernamentales, y existía en los imaginarios antropológicos e históricos, sin embargo sólo fue representada como una presencia colonial que, con el mestizaje y el paso del tiempo, terminó borrándose de la realidad nacional.

Ante la pregunta de ¿cómo se construye la idea de "lo negro" en México? en otros documentos ${ }^{2}$ he planteado que efectivamente esta idea está ligada a la producción disciplinar de la antropología y la historia mexicana del siglo xx, a las políticas públicas del Estado proteccionista, específicamente al indigenismo y a la idea del mestizaje. Pero no puedo dejar de lado que en esa construcción nacional lo negro-afrodescendiente siempre fue señalado como un elemento exterior al crisol de "razas" mexicano, como bien sostiene Elizabeth Cunin:

2 Véase Varela Huerta, 2014 y 2013. 
La categoría negro en México y recordar que se trata de una categoría práctica cuyo uso y significación están ligados a una inserción en el contexto sociohistórico mexicano. No pretendo así extraer a México de las dinámicas mundiales de la trata de personas, de la esclavitud, del colonialismo y de sus consecuencias, sino recordar que es necesario interpretar localmente categorías que son muy globales. Diferenciaré a los negros coloniales de los negros migrantes: los primeros están integrados al mestizaje y a la nación, como lo muestran la categoría de afromestizo o los trabajos de Gonzalo Aguirre Beltrán, aun cuando esta integración sea jerarquizada, racializada y marginalizante, y las poblaciones negras coloniales no formen parte del relato histórico nacional. En cuanto a los negros migrantes, a la vez negros y extranjeros, éstos son excluidos de la ideología del mestizaje y de la identidad nacional [Cunin, 2014: 26].

\section{Sobre la representación}

Si bien retomaré aquí centralmente la discusión sobre representación desde una perspectiva fincada en los estudios culturales y la relación de ésta con el lenguaje cinematográfico, también haré eco de las reflexiones de la crítica poscolonial para dar sentido después a mi mirada y análisis sobre La negrada, el filme que provocó de manera más compleja este análisis.

En términos teóricos, el concepto representación "es una parte esencial del proceso mediante el cual se produce el sentido e intercambio entre los miembros de una cultura. Implica el uso del lenguaje, de los signos y las imágenes que están en lugar de las cosas, o las representan" (Hall, 2010: 447). Por tanto, la representación -en este caso de las poblaciones negras-afrodescendientes- no es estática ni atemporal,

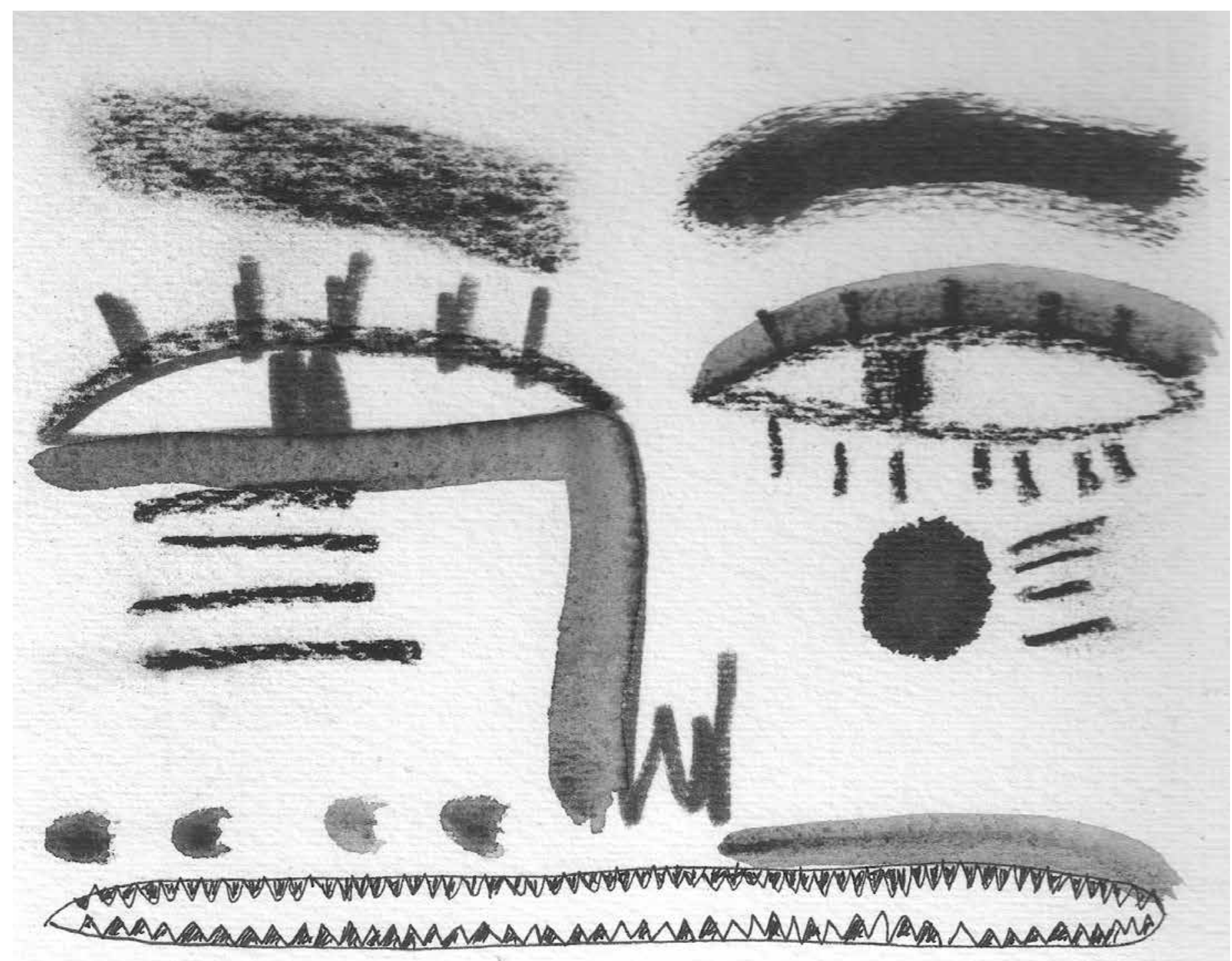


dado que, como sabemos, la "producción de cultura" está siempre en proceso, siempre hay deslizamientos de sentido, resemantizaciones y nuevas significaciones para el mundo que se habita y, por ende, se nombra.

La representación es de igual modo "la producción de sentido a través del lenguaje” (Hall, 2010: 457). De manera sencilla podríamos asentar que la noción de producción de sentido es una discusión que proviene de la lingüística y la semiótica, que tendrá efectos y que-con el giro discursivo-Foucault discutirá después en relación con la noción de regímenes discursivos:

Lo que le interesaba eran las reglas y las prácticas que producen enunciados con sentido y regulan el discurso en diferentes periodos históricos. Por "discurso" Foucault entiende:

"un conjunto de enunciados que permiten a un lenguaje hablar-un modo de representar el conocimiento sobre- un tópico particular en un momento histórico particular [...] El discurso es sobre la producción de conocimiento por medio del lenguaje. Pero [...] dado que todas las prácticas sociales implican sentido, y el sentido configura e influencia lo que hacemos -nuestra conducta- todas las prácticas tienen un aspecto discursivo" [Hall, 2010: 469].

Entonces, pienso en este sistema de representaciones no sólo en clave saussuriana sino en discursos y en las relaciones de poder (Foucault, 1974) que permiten que en ciertos regímenes discursivos la alteridad, lo otro, lo diferente, pueda ser representado en el lenguaje (escrito, hablado, audiovisual).

Cuando introduzco la noción de relaciones de poder es posible observar que esta representación de lo negro-afromexicano está asentada en formas específicas de orden hegemónico, que en el caso concreto de la alteridad negra-afrodescendiente en el cine mexicano están construidas y mediadas por aquello que podríamos llamar un racismo ingenuo -en el sentido de prácticas irreflexivas y naturalizadas en torno a qué significa ser racista y qué es el racismo, así como en la negación histórica de que en México existen dichas prácticas, porque "México es mestizo"- o en términos más concretos, la naturalización de los discursos racistas entre los creadores cinematográficos y el público de dichas producciones.
Al respecto, pienso en la diferencia entre creación de estereotipos y la tipificación, como lo señala Hall:

Los estereotipos retienen unas cuantas características "sencillas, vividas, memorables, fácilmente percibidas y ampliamente reconocidas" acerca de una persona, reducen todo acerca de una persona a esos rasgos, los exageran y simplifican y los fijan sin cambio o desarrollo hasta la eternidad. Este es el proceso que describimos anteriormente. Por consiguiente, el primer punto es: la estereotipación reduce, esencializa, naturaliza y fija la "diferencia" [Hall, 2010: 430].

Es decir, la diferencia fundamental entre mostrar ciertos rasgos y caricaturizarlos (estereotiparlos) y la necesidad de comprender y dar significado al mundo que nos rodea. En el caso específico de la representación mediática de lo negro-afrodescendiente en México lo único que ha sido exhibido es una serie de estereotipos racistas y racializantes de las culturas vinculadas a la noción de negro, afromexicano o afrodescendiente, como asienta Edward Said respecto a la construcción de Oriente por Occidente:

La relación entre Occidente y Oriente es una relación de poder, y de complicada dominación: Occidente ha ejercido diferentes grados de hegemonía sobre Oriente, como señala bastante bien el título del clásico del K.M. Panikkar, Asia and Western Dominance. Oriente fue orientalizado, no sólo porque se descubrió que era “oriental”, según los estereotipos de un europeo medio del siglo xix, sino también porque se podía conseguir que lo fuera -es decir, se le podía obligar a serlo [Said, 2002: 25].

Estos procesos de larga duración que impactan al generar un discurso sobre la alteridad nos dotan de elementos para analizar el caso de los negros-afromexicanos en el siglo xx.

Si bien hay trabajos recientes de antropología visual sobre la población de origen africano en México, ${ }^{3}$ ésta fue representada a través del largo discurso colonizador y excluyente de la nación mexicana como mestiza y con una temporalidad diferenciada en lo que respecta a la administración de las alteridades que la habitan. Siguiendo la tesis de discurso y poscolonialismo podemos asentar que:

3 En el ámbito de los documentales se encuentra Costa chica (2017), de Nicolás Segovia; Somos afromexicanos (2017), de Nadia Galavíz; Africanías (2015), de Rafael Rebollar, una reelaboración con imágenes del documental La tercera raíz (1992); Voces de mujeres de la Costa Chica (2013), de Natalia Gabayet y María Elisa Velázquez; Ébano, la tercera raíz en México (1999), de Eduardo Lizalde y en términos de antropología visual se encuentra Fandango o son de artesa (2015), de María Elisa Velázquez y José Luis Martínez Maldonado. Durante el 2018 se transmitió el programa televisivo Afroméxico, conducido por la senadora Susana Harp, cuyo objetivo es mostrar la herencia africana y afrodescendiente en México. 
El señalamiento de los aportes del colonialismo discursivo en esa construcción y su crítica al metarrelato del imperialismo han puesto de manifiesto que el colonialismo no constituye una estructura monolítica, sino que es más bien un entramado cultural en el que los actores e instituciones evidencian conflictos entre sí, más allá de compartir una serie de tópicos consensuados sobre el relato imperial, como la inferioridad del otro, su necesidad de conquista, etcétera. En ese marco, proyectos diversos como la ciencia, los negocios, la diplomacia, la filantropía y la religión se aúnan en pos de la construcción de la subalternidad del otro. Y el adjetivo representacional hace hincapié en la naturaleza de los insumos y de los productos de este proceso: textos, imágenes y actuaciones [Sánchez, 2014: 237].

Ahora bien ¿cómo funciona el cine documental o de ficción en la concreción específica de esta representación estereotipada y colonial del sujeto político negroafromexicano?

\section{La negrada}

El tono de piel que utilizo en la película (La negrada) no llega a lo totalmente negro que yo hubiera querido. Me dijeron que si me metía más iba a encontrar más negros, pero son más salvajes. Igual lo hago la próxima vez; allá se les llama azules o rojos, porque a cierta hora del día parece que desprenden un haz con esos tonos; bien bonito. Pero, o eran muy tímidos o muy salvajes, o no querían ni que me les acercara o me decían que les daba pena, explica el director, miembro del Sistema Nacional de Creadores de Arte [López, 2018].

Éste es un fragmento de la entrevista que Jorge Hernández, director de La negrada dio al periódico La Jornada cuando se estrenó el filme en salas nacionales, y muestra cómo la idea racializada de la población negra-afrodescendiente continúa tomando el color, lo salvaje, los territorios impenetrables y una estética que la relaciona con la naturaleza, como argumentos para construir los discursos racistas globales desde el siglo xIx.

La negrada cuenta la historia de dos mujeres de un pueblo en la Costa Chica de Oaxaca que están relacionadas por ser mujeres de Neri. Todos los personajes (madre, hijas e hijos, vecinos, enfermeras, doctoras, conductores, etcétera) tienen rasgos físicos visibles asociados al estereotipo dominante de lo afro. El hilo conductor de la cinta es la cotidianidad y los dolores de ambas por compartir a Neri y la enfermedad de una de ellas, que morirá hacia el final de la película.
Hasta este punto he realizado un brevísimo recorrido por el contexto de producción de un estereotipo colonial y racializado de "lo negro" en México. Esta representación no tuvo, durante muchas décadas, un sujeto político nacional al cual retratar. Aunque seguirán proyectándose diferentes filmes, documentales y archivos audiovisuales sobre la población negra-afromexicana en la actualidad, la mayoría forma parte del conocimiento antropológico que coincide temporalmente (aunque podríamos decir que también es parte de la producción de sentido) con el proceso político y de creación de una subjetividad negra-afromexicana entre la población de la Costa Chica.

Este proceso político, que finca una de sus principales tesis en la diferencia cultural, étnica e histórica, busca en términos pragmáticos el reconocimiento jurídico del pueblo negro-afromexicano y ha generado una discusión radicalmente diferente respecto de la identidad mexicana, el racismo y las emergencias étnicas e identitarias.

En más de 30 años de elaboración teórica y política por parte de las y los intelectuales negros-afromexicanos afincados en la Costa Chica, Veracruz, Coahuila y la Ciudad de México, entre otras ciudades del país, se apuesta por la autodeterminación, la nominación y, sobre todo, por la identificación de quién puede ser negro-afromexicano. Generalmente, por una tradición proveniente de Estados Unidos, se asoció el color a una identidad política, y a la idea de que una sola gota de sangre afro, indígena o de cualquier región colonizada convierte al sujeto en ciudadano etnicizado... sin embargo, una gota de sangre "blanca" no te permite ingresar y gozar de los privilegios de la blanquitud.

En mi análisis, y conforme al acompañamiento al proceso político negro-afromexicano, puedo señalar que a finales de los años noventa del siglo pasado, cuando este movimiento empezó a gestarse con el Encuentro de Pueblos Negros, la marca del color de piel era importante. Sin embargo, en las tres décadas siguientes, la discusión ha incluido la cultura, la residencia, la autoadscripción, el pasado familiar y social como elementos que permiten a ciertos sujetos autonombrarse parte de este colectivo. Si bien es cierto que dentro de esta lógica no es posible borrar las diferentes formas de discriminación y racismo que sufren sujetos racializados como "negros", el propio movimiento ha creado un amplio margen de autoadscripción en parte por estrategia política y en parte por una constitución teórica sobre qué significa en México ser negro-afromexicano.

Es en este contexto que aparece La negrada. Aquí me detengo un poco para decir que, de acuerdo con los elementos teóricos enunciados en las páginas 
anteriores, no considero esta cinta una obra hecha por una sola mente, por un solo hombre; la pienso y elaboro el análisis desde la noción de que es una obra cinematográfica construida con elementos de su tiempo social, político e ideológico; en ese sentido, también aclaro que no tengo ninguna filia ni fobia por el director o el grupo de trabajo. Conozco a una de las mujeres que actúan porque es parte fundamental del movimiento negro-afromexicano.

Lo que me interesa examinar de este film tampoco son sus cualidades estéticas, sino cuáles son, en todo caso, sus condiciones de posibilidad, su contexto y su contenido, tomando como base los elementos trabajados en los primeros apartados de este texto. Es decir, qué filmes y cuáles discursos preceden la representación de lo negro en México y cómo éstos afectan -en el sentido más teórico de esa palabra- la producción cinematográfica de la película que, nos guste o no, será un punto de referencia sobre lo negro-afromexicano y que debe mucho al esfuerzo político (y por ende perso-

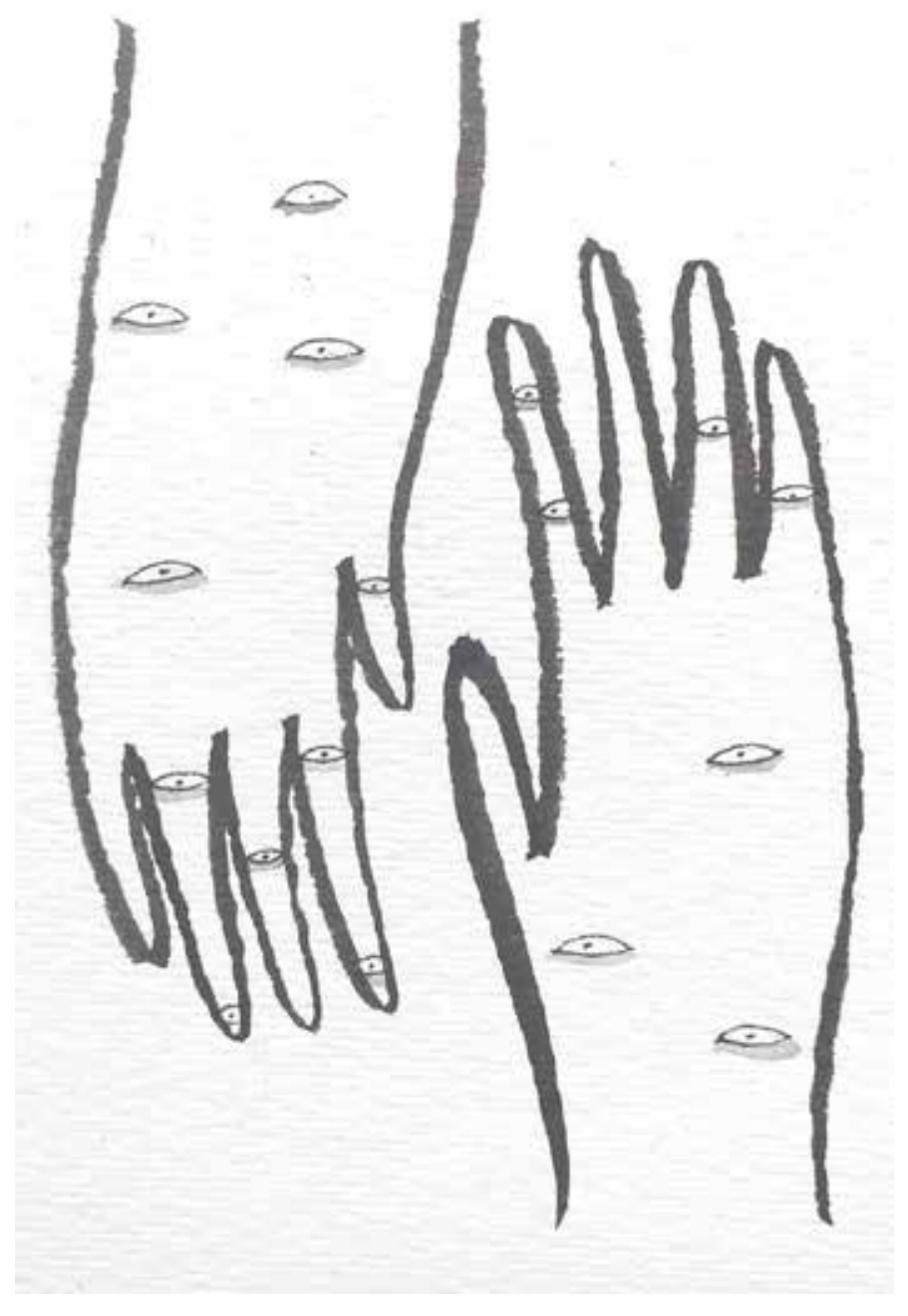

nal de muchas organizaciones y asociaciones civiles, sobre todo de la Costa Chica mexicana).

El filme de ficción inicia con la siguiente leyenda en letras blancas con un fondo negro:

La negrada. /sust/ f. Costa Chica, Mex/. Término que los negros se aplican a sí mismos. Surgió del disgusto que les produjo y les produce y el descalificativo racial.

En la Costa Chica llamar a un grupo de poblaciones y pobladores como "la negrada", efectivamente es una forma despectiva de señalar a los pueblos negrosafromexicanos; se usa como una descripción racista, clasista y racializada para englobar y estereotipar (que no tipificar) a las diferentes poblaciones y culturas que conviven en el espacio geográfico de la Costa Chica. Ahora bien, considero que el título de la película nunca tiene un efecto o concordancia con la historia que cuenta; es decir, está desligado de una potencia resignificante en su discurso.

El filme tiene bastantes aciertos en la forma de retratar algunas situaciones de la vida cotidiana de la población costeña (no sólo de la negra-afromexicana), como los medios para comunicarse con la cabecera municipal, el mercado de Pinotepa Nacional (Oaxaca), la escasez de turismo en las enramadas en algunas temporadas. Sin embargo, el cuerpo negro-afromexicano ocupa un lugar central en las diferentes tomas y secuencias de la historia, pero no cualquier cuerpo negro-afromexicano: una de mis primeras observaciones es que, pese a que en los diferentes pueblos de la región los rasgos físicos visibles estereotípicamente asociados con lo "negro" no definen la pertenencia política o cultural a dicha identidad, en el filme pareciera que en los pueblos y en todos los espacios sociales, estos rasgos son los únicos que pueden verse.

Una de las cuestiones más discutidas en la creación de la identidad social, cultural y política de los pueblos negros-afromexicanos es el gran repertorio sociocultural compartido con la población ñuu savi (mixteca de la Costa) y otras identidades indígenas que cohabitan la costa y que en este filme están borradas por un esfuerzo visual por mostrar la población afromexicana sólo a partir de los rasgos físicos.

Esto último es una trampa de la representación de la cual las diferentes asociaciones políticas negrasafromexicanas intentan escapar con el objetivo de no racializar la identidad precisamente por la idea de que ésta se finca en dos temporalidades específicas: primero, que en la actualidad, por estrategia, muchos activistas e intelectuales se autoadscriben por tradición, práctica cultural o vida común en pueblos particulares y, después, por la idea de un pasado 
compartido cuyos antecesores no fueron sólo personas esclavizadas sino también agentes de la construcción nacional.

Por eso, el mundo y los cuerpos colorizados de la costa oaxaqueña representados en La negrada interfieren de alguna manera en los esfuerzos de resignificación y estrategia política de los últimos 30 años de las asociaciones y, mediante una representación fincada en el color, reactualizan estereotipos sobre qué o cómo se es negro-afromexicano de la Costa Chica. Como señala una vez más Stuart Hall: "El cuerpo mismo y su diferencia eran visibles en todo el mundo y así proveían la 'evidencia incontrovertible' para una naturalización de la diferencia racial. La representación de 'diferencia' a través del cuerpo se convirtió en el sitio discursivo a través del cual gran parte de este "conocimiento racializado" se producía y circulaba" (Hall, 2010: 427).

En términos de la fotografía, con la exhibición de los cuerpos racializados se busca fijar una estética de lo negro-afromexicano vinculado a las labores rurales, a las playas, a las labores cotidianas de las mujeres, que reordenan un discurso racializante y genéricamente inamovible, pero con nuevas estéticas de la representación de la alteridad de las mujeres negrasafromexicanas.

En el resumen de la plataforma digital de reproducción de películas y series Amazon Prime, desde donde puede verse el filme, se lee:

El queridato es socialmente aceptado entre la población negra de la Costa Chica oaxaqueña. Juanita y Magdalena comparten su vida con Neri. La muerte de Juanita le dará a Magdalena la esperanza de ser su única mujer, sin embargo Neri tiene otros planes. Primer largometraje de ficción estelarizado en su totalidad por afrodescendientes de diferentes comunidades de la Costa Chica mexicana.

Lo anterior me lleva a pensar en el argumento central de la película: el queridato. Institución cultural de la Costa Chica que se finca en las prácticas hegemónicas de los varones para tener dos familias, no sólo dos esposas, en el mismo pueblo o en pueblos cercanos. Esta práctica es tolerada, pero no aceptada por las mujeres, sobre todo en los últimos años, cuando activistas feministas o que luchan por las mujeres cuestionan supuestas tradiciones como el rapto o el queridato, con el objetivo de que dejen de exhibirse como tradiciones de los pueblos negros-afromexicanos y se piensen como formas machistas que deben ser repensadas en el interior de los propios pueblos. Beatriz Amaro Clemente, activista que se autodenomina mujer negra, asegura al respecto:
El queridato es una forma más de la violencia que se ejerce desde el machismo, porque se continúa con la idea de que el hombre puede dejarme, violentarme sin tomar en cuenta mis derechos como mujer. Y como mujeres activistas nos preguntamos ¿cómo queremos ser representadas en la cultura?" [Amaro Clemente, entrevista personal, diciembre 2018].

Y durante la entrevista continúa leyendo su opinión, publicada en Facebook:

La película hace un planteamiento muy superficial de nuestras tradiciones y realidades. No voy a negar que la mayoría de nuestras comunidades se encuentran en situaciones de pobreza y que el queridato existe, y es y ha sido considerado por muchos como parte del patrimonio cultural del pueblo negro. Esta manifestación de profundo machismo es cada vez menos frecuente, lo que se me hace peligroso es el hecho de que muchos de quienes vean este filme se queden con la idea de que es la constante en las comunidades negras de la Costa Chica cuando no lo es. Mi yo feminista se inclina a pensar que pudo haber explotado aún más las historias de Magdalena y Juana y menos la de Neri, las dificultades a las que nos enfrentamos para acceder al sistema de salud, a la falta de oportunidades y al machismo imperante. Las mujeres afromexicanas estamos luchando por el ejercicio de nuestros derechos [Amaro Clemente, entrevista personal, diciembre 2018].

Lo anterior adquiere sentido en relación con el siguiente diálogo entre los personajes más jóvenes, hijos de las relaciones de queridato entre los protagonistas, cuando se preguntan por Neri, el varón de la película con dos familias:

-Él tiene como cinco mujeres regadas por toda la Costa, todas con hijos. Ya casi ni lo vemos al muy verga.

- ¿Y tú vas a ser igual? (pregunta la hija de Neri)

-Claro; las tradiciones no se van a perder tan fácil.

A lo que el joven personaje homosexual feminizado responde:

— ¿Tradiciones? Mejor hay que probar cosas nuevas.

En este filme el mundo femenino se muestra afincado en la labor doméstica y afectiva como supuesto elemento disruptor de las relaciones de género por centrarse en una forma de parentesco no monogámica (según señaló en varias entrevistas Pérez Solano), sin embargo, uno de sus desaciertos es que esto reifica el lugar de la mujer como un ser pasivo aguardando la respuesta del mundo masculino o en la espera eterna de los turistas en sus puestos de trabajo. La mayoría de las tomas de las actividades de las mujeres está 
vinculada a las labores de cuidado. En el caso de Neri, el varón protagonista de la película, éste se muestra repetidamente en la hamaca, descansando.

Ambos ejemplos vuelven a la construcción de las mujeres y los varones negros-afromexicanos como pueblos que tienen los recursos ecológicos a la manoy, por ende, hacen poco esfuerzo laboral, un estereotipo global para representar a la población afrolatinoamericana que reactualiza los discursos racistas. Nada más lejos de los diferentes mundos de trabajo que se viven en la región Costa Chica y que han sido documentados por los propios activistas, la antropología o el periodismo, ya que se conoce que las actividades productivas en la Costa van desde la agricultura, los servicios turísticos, la cultura, la ganadería o el comercio, incluyendo los ilícitos.

En un juego de fotografía etnográfica y artística, el filme termina recreando las ideas que históricamente fueron asociadas a los pueblos negros-afrodescendientes, como quedó de manifiesto en la cita textual de Hall (2010: 426) reproducida en el apartado Antropología mexicana.

Otro acierto que traigo a colación de este filme son dos denuncias sobre racismo y violencia intrafamiliar que se enlazan con la historia del queridato, a pesar de que se construye una estética de la pobreza a través de las imágenes, la denuncia está presente y también se revela en una escena la lucha política negra-afromexicana.

El problema central en esta película no es que el equipo que la realizó tenga la vocación de representar de forma racista a la población negra-afromexicana, sino que la naturalización del racismo que ordena el discurso sobre las diferencias no es cuestionado por los medios de comunicación y las instituciones públicas y privadas. Podemos observar de manera recurrente cómo se construyen, a través de fotografías, historias de vida, videos caseros y cortos informativos las narraciones sobre la diferencia (por ejemplo, el caso de los migrantes hondureños), sin pensar en la triada de clasismo, racismo y misoginia que hoy más que nunca amenazan la vida común.

La negrada es una compilación de cómo hoy los discursos antirracistas han sido marginados y continúan vigentes en términos de la construcción de hegemonía, naturalización y resignificación del racismo:

En términos del colonialismo, subdesarrollo, pobreza y racismo motivado por el color, la presencia europea es aquella que, de una manera visual, ha posicionado al sujeto negro dentro de sus regímenes dominantes de representación, el discurso colonial de aventuras y de exploración, la novela de lo exótico, la etnografía y la mirada del viajero. Las lenguas tropicales del turismo, los folletos de viaje, Hollywood y lo violento, lenguajes pornográficos de la ganja y la violencia urbana [Hall, 2010: 357].

\section{Conclusiones}

Vuelvo a la idea de representación como espacio de ejercicio de poder y construcción de hegemonía para asentar que la concatenación de discursos en una cinta como la que analicé brevemente nos permite observar de forma clara no la obra de un hombre sino la reactualización y resignificación de discursos racistas que circulan con normalidad, que normalizan la idea de la diferencia y la otredad como una temporalidad no compartida por la mayoría mestiza mexicana. Al finalizar la película, una leyenda asienta "La falta de rasgos específicos como idioma, formas de gobierno y territorio han descartado su presencia como pueblo, nación o cultura" (La negrada, 2018).

Una vez más, esta población es definida sin etnicidad, sin identidad colectiva por parte del equipo de la película, lo cual abreva a la idea de que en efecto no tienen rasgos específicos, lo que ha sido uno de los motores de la movilización: demostrar que sí los tienen y los practican, como elaboro en diversos escritos anteriores a éste, recuperando la noción de Yúdice (2002) de la cultura como recurso político, acción realizada por diversos colectivos afromexicanos.

Y no sólo actualizan y normalizan los discursos racistas: en el caso de La negrada como producto comunicacional de su época, también observamos cómo la representación de las relaciones de parentesco entre algunos pobladores negros-afromexicanos de la Costa pueden convertirse, como bien señala Amaro Clemente en la constante para representar a estos sujetos. Lo anterior tiene efectos nocivos para dicho grupo poblacional, uno de ellos es seguir construyendo estereotipos de mujeres negras-afromexicanas como sujetos sufrientes, sin posibilidad de cambiar sus relaciones en entornos machistas.

Otras mujeres y hombres activistas también aseguran que uno de los aciertos del filme es visibilizar a este grupo étnico a nivel nacional; alentar a hablar de sus luchas, olvidos y racismos. Lo que no debemos olvidar es el efecto del cine como medio de comunicación masiva y creación de estereotipos; si bien esta cinta muestra al grupo enunciado, la pregunta que flota en el aire es la misma que se hacen las mujeres negras-afromexicanas y que aquí se presenta a partir de la voz de Beatriz Amaro "¿cómo queremos ser representadas?". 


\section{Fuentes}

Cunin, Elisabeth

2014 Administrarlosextranjeros:raza, mestizaje, nación. Migraciones afrobeliceñas en el territorio de Quintana Roo, 1902-1940, Centro de Investigaciones y Estudios Superiores en Antro-

Flanet, Veronigue pología Social, México.

1977 Viviré si Dios quiere. Un estudio de la violencia en la mixteca de la costa, Consejo Nacional para la Cultura y las Artes, Dirección General de Publicaciones / Instituto Nacional Indigenista, México.

Foucault, Michel

1974 Microfísica del poder, Ediciones de La Piqueta, Madrid.

HALL, STUART

2010 Sin garantías. Trayectorias y problemáticas en estudios culturales, Eduardo Restrepo, Catherine Walsh y Víctor Vich (eds.), Instituto de Estudios Sociales y Culturales Pensar, Universidad Javeriana/Instituto de Estudios Peruanos/Universidad Andina Simón Bolívar sede Ecuador/Envión Editores, Bogotá y Quito.

López, Sergio Raúl

2018 "La negrada, filme de ficción que aborda el tema de la tercera raíz en México”, en La Jornada, 10 de agosto <https: / /www.jornada.com. $\mathrm{mx} / 2018 / 08 / 10 /$ espectaculos /aO7n1esp $>$.

Martínez Montiel, Luz María

2008 Africanos en América, Editorial Ciencias Sociales, La Habana.

Nahmad Rodríguez, Ana Daniela

2007 "Las representaciones indígenas y la pugna por las imágenes. México y Bolivia a través del cine y el video", en Latinoamérica. Revista de Estudios Latinoamericanos, núm. 45, pp. 105-130.
PÉrez Montfort, RicARdo

2007 Expresiones populares y estereotipos culturales en México. Siglos XIX y Xx. Diez ensayos, Centro de Investigaciones y Estudios Supe-

Pulido Llano, Gabriela

2010 Mulatas y negros cubanos en la escena mexicanas (1920-1950), Instituto Nacional de An-

SAID, EDWARD tropología e Historia (Col. Científica), México.

2002 Orientalismo, Random House Mondadori, Barcelona.

Sánchez, Emiliano G.

2014 "Reflexiones en torno al concepto de representación y su uso en la historia cultural", en Questión. Revista especializada en periodismo y comunicación, vol. 1, núm. 42, pp. 228-241 <https: / / perio.unlp.edu.ar/ojs/index.php/ question/article/view/2130>.

Silva Escobar, Juan Pablo

2013 "La época de oro del cine mexicano: la colonización de un imaginario social", en Culturales, vol. VII, núm. 13, pp. 7-30.

Varela Huerta, Itza Amanda

2013 "Notas preliminares para el estudio del proceso de reconocimiento de la población morena/afromexicana en el sur de México", en María de Lourdes Ghidoli y Juan Francisco Martínez Peria (comps.), Estudios afrolatinoamericanos, nuevos enfoques multidisciplinarios, Universidad de Buenos Aires, Argentina, pp. 399-410.

VAREla Huerta, ItZa Amanda

2014 "Proceso de identificación de los pueblos negros de la Costa Chica en México: usos de la cultura en la constitución de su etnogénesis", en Intersticios de la política y la cultura, vol. 3,

YÚdICE, GeORGE núm. 5, pp. 56-67.

2002 El recurso de la cultura. Usos de la cultura en la era global. Gedisa, Barcelona. 